Dalmarco G., Teles V., Uguen O., Barros A.C. (2021) Digital Innovation Hubs: One Business Model Fits All?. In: Camarinha-Matos L.M., Boucher X., Afsarmanesh H. (eds) Smart and Sustainable Collaborative Networks 4.0. PRO-VE 2021. IFIP Advances in Information and Communication Technology, vol 629. Springer, Cham. https://doi.org/10.1007/978-3-030-85969-5_41

\title{
Digital Innovation Hubs: One Business Model Fits All?
}

\author{
Gustavo Dalmarco ${ }^{1}$, Vasco Teles ${ }^{1}$, Olivia Uguen ${ }^{2}$, Ana Cristina Barros ${ }^{1}$ \\ ${ }^{1}$ INESC TEC - Institute for Systems and Computer \\ Engineering, Technology and Science, Rua Dr. Roberto Frias \\ 4200 - 465, Porto, Portugal \\ \{gustavo.dalmarco, vasco.b.teles, ana.c.barros\}@inesctec.pt \\ ${ }^{2}$ BLUMORPHO \\ 8 , rue de l'Isly, Paris 75009 - FRANCE \\ uguen@blumorpho.com
}

\begin{abstract}
Digital transformation is critical for the competitiveness of SMEs. Digital Innovation Hubs (DIHs) aim to regionally support companies in the development of new products, processes, or services, providing access to advanced technologies. Since DIHs have to be financially sustainable, it is important to discuss which business models are put forward in such complex arrangements. Our main goal is to analyse how DIHs, specialized in Industry 4.0 technologies and services, create, offer, and capture value. The research was conducted through a documentary analysis of reports about DIHs' Business Models, generated by three European initiatives (encompassing more than 300 DIHs). Results demonstrate that one Business Model does not fit all, since regional characteristics, which vary among different DIH's, are the main drivers to define value creation, offer and capture. This work aims to provide DIH managers insights to help them develop sustainability strategies.
\end{abstract}

Keywords: Business Model; Digital Transformation; Digital Innovation Hub; Innovation.

\section{Introduction}

The current phase of the digital transformation, described by initiatives such as Industry 4.0, Smart Manufacturing and Industrial Internet of Things (IIoT), among others, is receiving increasing attention from manufacturing industries. Through Industry 4.0, companies aim to reduce operational costs while increasing productivity, quality, and flexible production supported by the intensive use of technologies in production and commercialization processes [1, 2]. Improvements are achieved through the integration of physical and virtual objects that allow a real-time monitoring of people and machinery, adding to the interconnectivity between machines, products, intelligent systems, and interrelated solutions [3, 4]. Supported by different models such as the Reference Architectural Model Industry (RAMI) 4.0, industry 4.0 enables the transfer of the decision-making process down to machine level, deploying a self-regulating production system $[5,6]$. The digitalization of products and processes allowed by improvements in sensing and communication are key for advanced decision-making 
428 G. Dalmarco et al.

processes [7]. The application of digitalization in companies can occur in phases or levels of technology implementation, involving: 1) the digitalization of processes and integration of the value chain; 2) the digitalization of products and services; and 3) the generation of new digital business models [8].

To support companies through its digital transformation, DIHs offer a wide range of services through an ecosystem organization model [9]. DIHs are usually formed by a network of Research and Technology Organizations (RTOs), universities, and technology providers, among others, acting as one-stop-shops to offer customized solutions to companies [10]. DIHs can be considered a Virtual Breeding Environment (VBE) [11], since they represent an association of different organizations with complementary skills and resources. There are currently already 664 DIHs across 39 European countries identified in the European Union (EU) Digital Innovation Hubs Catalogue [12]. The main challenge of DIHs, given its complex arrangement of technologies and agents, is to define a proper business model for their operations.

Business model (BM) is a logical structure to create value for all stakeholders of a business [4] and includes, in general, four main areas of an organization: a) customers, b) value offer, c) infrastructure, and d) financial viability [13]. DIHs, however, usually only stimulate partnerships among the agents of its network and SMEs, while services are offered in a one-to-one relation between the company (demand agent) and the RTO/ University/Tech Provider. One of the tools used to portray an organization's business model is the Business Model Canvas [13] which presents a visual structure that allows the presentation of the critical elements for business operation. This tool, however, does not always address all the relevant characteristics of an organization with complex ecosystems such as DIHs. Consequently, other tools, more suitable to accommodate DIHs' BM specificities, had to be identified.

Given this scenario, our objective is to analyse how DIHs, specialized in Industry 4.0 technologies and services, create, offer, and capture value, by identifying business model patterns. This work aims to contribute to the theoretical body of knowledge on business model innovation and provide DIH managers insights to help them better steer their activity. The next section presents the theoretical background about Business Model Analysis and DIHs, followed by the Research Method in section 3. Section 4 presents the main results, followed by the concluding remarks on section 5 .

\section{Literature Review}

The main objective of a BM is to define how a company addresses aspects of its business (physical, human, and material resources) to create and deliver value to its customers [14]. In addition, it also describes how to attract clients willing to deliver value to the company (capture value), generating financial results to the company [15]. Here, the business model framework, also known as Business Model Canvas (BMC) [13], presents a visual structure of a BM's basic elements, and its interrelations, thus emphasizing the critical elements of business success. The BMC is represented by nine blocks $[4,13,16]$, describing:

- Customer segments: groups or segment of clients the company aims to sell its product / service to; 
- Customer relationships: how the company will interact and create loyalty within its clients;

- Revenue streams: company's income sources;

- Key Activities: company's the main activities necessary to deliver its value proposition and implement its business model;

- Key Resources: company's key assets, e.g. exclusive machinery, Intellectual Property, or highly trained employees, necessary to run its key activities;

- Key Partners: company's external partners (suppliers, partnerships, outsourcing) necessary to run its key activities;

- Cost Structure: company's main expenses to run its business model;

- Value Proposition: company's unique solution - either product or service that will be offered to the market. It should address a problem or create value to company's customer segment.

The BMC presented by [13], however, is mainly suited for companies with one single product, such as start-ups, or companies with independent products. Here, each product has its own business strategy, aiming to maximize its individual rentability. A DIH, however, is a much more complex organization, since on the one hand it has its own technological specialization, according to regional demands, and on the other it orchestrates a set of different actors with different business strategies [17]. DIHs are network organizations, usually managed by public organizations, constituted of regional or national innovation actors. Consequently, DIHs must have a broader strategy to encompass different types of value streams, also addressing social and public impacts.

Therefore, in order to analyse the main characteristics of DIH business models, two other BM Canvases will be jointly used: the Public Private Partnerships (PPP) Canvas [15] and the Service Logic BMC (SLBMC) [18]. Adding to the BM Canvas, the PPP Canvas has four extra blocks describing [19]:

- Extended Beneficiaries: Describes organizations or other type of entities who receive indirect benefits of the DIH's services;

- Impact: Describes how the services offered by the DIH benefits its own region through the creation of social, public, or environmental value;

- Governance: Describes the DIH governance model with its associates;

- Business Ecosystem: Describes how the DIH interacts with regional/national business ecosystems.

On the other hand, the SLBMC is also composed of nine building blocks, just like the original BMC, but here, each block contains two perspectives: the organisation's (as usual) and the customer's. The customer perspective was added to make organisations analyse their business from the perspective of customers' activities, practices and experiences, thus focusing on the services they can provide to the customers [18].

Considering the different ways to analyse and detail a business model, in addition to the specific characteristics of industry $4.0[20,21]$, our analysis will describe and compare how DIHs specialized in Industry 4.0 create, deliver, and capture value to and from its associates and companies served: (1) value creation represents the DIH's main activities, identifying its operation, resources, and relationships with key partners; (2) value offering represents how the services offered by the DIH satisfy customers' needs; 
430 G. Dalmarco et al.

(3) finally, value capture refers to how the DIH define and engage with its customers, determine demands and needs, how customers perceive value delivery and what type of relationship the DIH must maintain with the customers served by its associates. A key aspect here is not only analysing the BM elements, but how their interrelation demonstrates the organisation's full strategy.

\section{Research Method}

Following this work's objective, the research question is as follows: What are the relevant characteristics of value creation, offer and capture for DIHs specialized in Industry 4.0 technologies?

The research design was developed through the following steps: first, we reviewed the literature about Business Model Design, Business Model Canvas and PPP Canvas in order to identify the main elements of Business's Value Creation, Value Offer and Value Capture. Second, we carried out an exploratory research based on document analysis [22], mainly based in project reports. Three project reports were analysed: (1) BEinCPPS - Business Experiments in Cyber Physical Production Systems [23], describing 5 DIHs; (2) Smart4Europe2 - Catalysing Digitisation throughout Europe [24], describing 5 DIH networks; and (3) DIH.NET Community [25], presenting survey data of 300 DIHs.

All documents provided rich information about DIH business models, being reports 1 and 2 based on an in-depth analysis of specific DIHs, while report 3 conducted a survey with 300 DIHs. This analysis was combined with DIH's websites and other reports publicly available. In the next sections we present the consolidated analysis of all DIHs, presenting the main characteristics of value Creation, Value Offer, and Value Capture for DIHs specialized in Industry 4.0 technologies and services.

\section{Research Results}

In order to consolidate the data from different documents, our analysis focused on describing the main characteristics of value creation, value offer, and value capture of the different DIHs. As the main objective of DIHs is to support companies in the improvement of their production processes, products or services, using digital technologies [12], the discussion about value creation, offer, and capture aims to foster the development of new DIH, or support existing ones with benchmark analysis.

\subsection{Value Creation}

In order to be competitive and sustainable, a DIH must create value to its region according to local demands and governmental goals. As could be observed, most analysed DIHs create value through five main activities: (1) Ecosystem building, scouting, brokerage, networking - here collaborative platforms such as DIH4Industry, DIHNET and AI4EU, among others, increase DIH's competences; (2) Collaborative 
Research among companies and DIH's associates; (3) Education and skills development; (4) Concept validation and prototyping; and (5) Testing and validation. These activities, however, do not create value by itself. They should be aligned with different strategic definitions, as described below:

- Regional characteristics and industrial demand;

- Partners and how they complement their resources;

- Legal arrangement;

- Vision, mission and expected impact;

- Main services, technologies and facilities;

- Cost structure.

In addition to these strategic definitions, issues related to the legal structure and modus operandi of the DIH emerged. E.g., the main identified DIH strategic decision was to be established through a public or non-profit organization, such as RTOs, thus sharing its facilities and cost structure. This type of organization usually assures high commitment and low cost for companies, as well as high trust for the involved stakeholders. Another form of legal organization is through the DIH network, without a formal structure. Here one organization is defined as lead partner, which officially represents the whole network. In both cases an executive managing team could be arranged among the most active DIH partners, committed by a memorandum of understanding that can also describe the DIH main activities and processes (such as service portfolio, admission process of service providers, governance, dissemination policy, conflict of interests, financing sources, advisory group, etc.).

\subsection{Value Offer}

Although addressing the needs and demands of a specific region, differences in DIHs value offer represents their own competitive advantage. Companies, as clients, have a critical eye when choosing a DIH to partner with. Consequently, geographical proximity does not necessarily mean companies will not look for other DIHs with a better value offer. Therefore, as the value offer of DIH is mainly represented by how the services offered by the DIH satisfy customer needs, the greater the quality of the service, the greater the chance of a certain DIH to attract more clients.

In this sense, the most observed strategy is defined by training services and workshops, where companies can discuss how the services offered by the DIH may address their specific need. The development of training sessions in solutions identified as key to a specific sector shall bring the attention of a specific cluster of companies, opening an opportunity to demonstrate how new technologies work and how could it be applied to other companies. Such training activities, often carried out through handson experience in demonstrations labs, may result into future services to implement the technologies presented, thus upgrading company's technology maturity level. In a similar way, workshops open to specific groups of companies may be an opportunity to present certain technologies in a 'test-before-invest' methodology, consolidating the $\mathrm{DIH}$ as the reference organization for a particular technology. Consequently, through unique value proposition, DIHs build on new business models for the sustainability of their activities. 


\subsection{Value Capture}

Given the current sustainability challenge, DIHs must define strategies to improve value capture. One of the main activities in this sense is to properly disseminate the benefits of the DIH to its region, engaging in dissemination activities. Besides using online platforms, DIHs also offered open seminars, technology demonstration sessions, and workshops to representatives of the different regional industrial sectors, using the opportunity to present its activities, how it could add value to companies, and in which ways companies could engage in activities with the DIH partners. Here the identification of who are the DIH's main clients and industrial sectors, adding to which are the most relevant services offered by the DIH, supports the deployment of a value capture strategy.

Another important issue identified is the definition of the DIH revenue streams, as they should define a proper strategy for its individual sustainability. Although the DIHs main funding sources are still public (either regional, national or European), private funding is one option for half of the DIHs analysed. Here we observed not only the payment of specific services by SMEs, but also periodic fees or subscription taxes payed by the DIH network members (who have the advantage of being part of the network, thus having access to public funding opportunities). Membership services could also be offered to partner companies, who in turn could have access to technology demonstration, dedicated workshops and assessment services. Here the main strategic movement is agility, keeping the DIH updated in a very fast-moving and complex environment, while also remaining in line with the emerging needs of companies and the corresponding answers provided by technology and knowledge.

\section{Final Remarks}

DIHs are public-funded collaborative networks that, guided by an open innovation strategy, support and promote partnerships between SMEs and technological intense organizations towards increasing the digitalization of industry. In recent years, Europe observed a rapid growth in the number DIHs, each one with its own characteristics, technologies, and services. These initiatives are usually led by non-profit organizations as RTOs or universities, mostly regionally anchored to better address the regions' demands and needs. Financial sustainability is a common goal to DIHs to which they develop their own BM.

Based on different BM frameworks, the present study suggests patterns on the way DIHs dedicated to Industry 4.0 implementation create, offer, and capture value. Results demonstrated that DIHs use different BMs to create, offer and capture value. Given their VBE behaviour, which encompasses particular strategies of different organizations, having a clear BM support DIH's to be recognized as an important agent of regional and national innovation system. In this sense, this study was able to show that:

- despite differences in competences, regional contexts, manufacturing sectors, and needs and demands, it is apparent that the value creation is achieved through five main activities: Ecosystem building, scouting, brokerage, networking; 
Collaborative Research among companies and DIH's associates; Education and skills development; Concept validation and prototyping; Testing and validation closely aligned with strategic DIH decisions;

- the value is usually offered by a set of services which aim to capacitate companies through the implementation technological solutions to improve their processes, while increasing their digital maturity, as well as through workshops, demonstrations, and training, which also act as vehicles to better understand those companies' challenges;

- finally, the value is captured as revenues, paid by customers for the services DIHs provide, or e.g., fees giving access to the network's activities, knowledge materials, demonstration installations, etc. These private funding in the form of revenues play a very relevant role toward financial sustainability, since after a ramp-up period, it is expected that the public funding for DIH operation decreases or even ceases.

With this work, we contribute to the body of knowledge about regional DIHs and the way they operate - concerning the way they create, offer, and capture value. These results also support DIH managers and customers to better understand the main patterns emerging from their operation. As questioned by the title if "one business model fits all?", our work concludes that regional characteristics - such as innovation behaviour, collaborative culture, trust, and also funding sources - are the main distinguishing drivers composing each DIH business model. In addition, as DIHs offer a combination of members' individual competences, similarities in their own business models are key to define the DIH business model as a whole. This leads each DIH to be more efficient addressing regional needs and demands while differentiating DIHs from one another in the way they operate. Future research in this field could address the influence of DIHs in wealth creation and contributions to GDP at regional and national level.

\section{Acknowledgements}

This research received funding from European Union Framework Programme for Research and Innovation Horizon 2020 under Grant Agreement nos. 952003 (AI REGIO), 872111 (Smart4Europe2), and 825640 (DIHNET.EU)

\section{References}

1. Saucedo-Martínez JA, Pérez-Lara M, Marmolejo-Saucedo JA, et al (2018) Industry 4.0 framework for management and operations: a review. J Ambient Intell Humaniz Comput 9:789-801. https://doi.org/10.1007/s12652-017-0533-1

2. Dalenogare LS, Benitez GB, Ayala NF, Frank AG (2018) The expected contribution of Industry 4.0 technologies for industrial performance. Int J Prod Econ 204:383-394. https://doi.org/10.1016/j.ijpe.2018.08.019

3. Safar L, Sopko J, Bednar S, Poklemba R (2018) Concept of SME business model for industry 4.0 environment. TEM J 7:626-637. https://doi.org/10.18421/TEM73-20

4. Kiel D, Arnold C, Voigt KI (2017) The influence of the Industrial Internet of Things on business models of established manufacturing companies - A business level perspective. Technovation 68:4-19. https://doi.org/10.1016/j.technovation.2017.09.003

5. Hermann M, Pentek T, Otto B (2016) Design principles for industrie 4.0 scenarios. In: 
434 G. Dalmarco et al.

49th Hawaii International Conference on System Sciences. IEEE, pp 3928-3937

6. Hernández E, Senna P, Silva D, et al (2019) Implementing rami4. 0 in production-a multi-case study. In: International Conference of Progress in Digital and Physical Manufacturing. Springer, pp 49-56

7. Bienhaus F, Haddud A (2018) Procurement 4.0: factors influencing the digitisation of procurement and supply chains. Bus Process Manag J 24:965-984. https://doi.org/10.1108/BPMJ-06-2017-0139

8. Oztemel E, Gursev S (2018) Literature review of Industry 4.0 and related technologies. J Intell Manuf. https://doi.org/10.1007/s10845-018-1433-8

9. Antonopoulos CP, Keramidas G, Tsakanikas V, et al (2020) Capacity Building Among European Stakeholders In the Areas of Cyber-Physical Systems, IoT \& Embedded Systems: The SMART4ALL Digital Innovation Hub Perspective. In: 2020 IEEE Computer Society Annual Symposium on VLSI (ISVLSI). IEEE, pp 464-469

10. DEI (2017) Digital Innovation Hubs: Mainstreaming Digital Innovation Across All Sectors

11. Camarinha-Matos LM, Afsarmanesh H, Galeano N, Molina A (2009) Collaborative networked organizations-Concepts and practice in manufacturing enterprises. Comput Ind Eng 57:46-60. https://doi.org/https://doi.org/10.1016/j.cie.2008.11.024

12. DIH Digital Innovation Hubs Catalogue. https://s3platform.jrc.ec.europa.eu/digitalinnovation-hubs-catalogue. Accessed 29 Apr 2021

13. Osterwalder A, Pigneur Y (2010) Business model generation: a handbook for visionaries, game changers, and challengers. John Wiley \& Sons, New Jersey

14. Morris M, Schindehutte M, Allen J (2005) The entrepreneur's business model: Toward a unified perspective. J Bus Res 58:726-735. https://doi.org/10.1016/j.jbusres.2003.11.001

15. Teece DJ (2010) Business models, business strategy and innovation. Long Range Plann 43:172-194

16. Trimi S, Berbegal-Mirabent J (2012) Business model innovation in entrepreneurship. Int Entrep Manag J 8:449-465. https://doi.org/10.1007/s11365-012-0234-3

17. Hervas-Oliver J-L, Gonzalez-Alcaide G, Rojas-Alvarado R, Monto-Mompo S (2020) Emerging regional innovation policies for industry 4.0: Analyzing the digital innovation hub program in European regions. Compet Rev An Int Bus J

18. Ojasalo J, Ojasalo K (2018) Service logic business model canvas. J Res Mark Entrep 20:70-98. https://doi.org/https://doi.org/10.1108/JRME-06-2016-0015

19. PPP Lab (2016) PPPCanvas User Guide

20. Müller JM, Buliga O, Voigt KI (2018) Fortune favors the prepared: How SMEs approach business model innovations in Industry 4.0. Technol Forecast Soc Change 132:2-17. https://doi.org/10.1016/j.techfore.2017.12.019

21. Müller JM, Däschle S (2018) Business model innovation of industry 4.0 solution providers towards customer process innovation. Processes 6:1-20. https://doi.org/10.3390/pr6120260

22. Bowen GA (2009) Document analysis as a qualitative research method. Qual Res J

23. BEinCPPS. http://www.beincpps.eu/. Accessed 30 Apr 2021

24. Smart4Europe. https://smart4europe.eu/. Accessed 30 Apr 2021

25. Digital Innovation Hub Networks. https://dihnet.eu/. Accessed 30 Apr 2021 